\title{
Urban growth and urban infrastructure relations in Turkey
}

\author{
S. Turgut \\ Department of Urban and Regional Planning, \\ Yıldız Technical University, Turkey
}

\begin{abstract}
Urban infrastructure relations are composed of the necessary transmission channels and facilities for a healthy and sustainable urban environment in terms of space and society in a settlement. The existence of a healthy and sustainable urban environment could only occur by reducing the problems of infrastructure relations to a minimum level, by abolishing these problems and taking precautions for the possible ones, and by analyzing these problems correctly. Correctly interpreting and classifying the data about infrastructure problems and taking them into consideration in the decision making process are as important as the data gathering process. The EU has determined four important strategic aims for "sustainable urban development". One of these aims is the physical conditions, and infrastructure. In order to achieve these aims, a relation between urban infrastructures, urban planning decisions, and the construction of the superstructure must be established. The term "infrastructure systems" is commonly used for stating sewage projects, drinking water, electricity, natural gas, telephone, and telecommunication projects like cable TV. Infrastructure, symbolizing the development level of a country, is a topic that directly affects the health standards, the life standards, and the environment quality of people. Therefore, it is impossible to overlook infrastructure in creating a composed urbanization.

In this paper, the urban infrastructure factor in Turkey will be elaborated in the context of urban growth, and particularly the planning process, in terms of the planning levels that are defined by law. The problems will be determined and will be opened to discussion.

Keywords: infrastructure, urban growth, urban management.
\end{abstract}




\section{Introduction}

As the population and urbanization augment, parallel to the transformation of cities into a metropolis, the importance of infrastructure and its complex structure gradually increases. As the urban forms and relations spread and become more active, the infrastructure investments, projects and applications become the key words of urban life quality and sustainability. Although infrastructure projects are almost the guarantees of a healthy urban life, they create a serious economic responsibility for the municipalities. Once these projects are designed and planned in compliance with the technical standards, they are constructed and opened to business. After this point, they cause additional expenses for repair and care. They also cause expenses even after their economic life ends. The corporations that offer infrastructure services are responsible of providing electricity, water, natural gas, communication, etc. In other words, they are responsible of serving for the equipment that the citizens actually possess. Especially in the new buildings, the connection of the building to the existent infrastructure often damages the superstructure, such as roads or pavements in the area. Therefore, infrastructure corporations keep making new excavations as the lines are damaged [1].

Infrastructure encounters problems in functionality due to the lack of integrated infrastructure plans and strategies in application, the rapidly changing urban planning decisions, and the decisions that are made segmentally. Besides, these negativities constantly get stronger, since some corporations have the wrong information about the places of infrastructure lines. This also augments the waste of resources, and it even causes loss of some lives. Another situation is that sometimes, the corporations are mistaken about how their work does not concern the other corporations. This does not only affect the serving process in a very bad way, but also, it creates the possibility of two corporations of infrastructure and superstructure witnessing each other in the same road axis, being unaware of each other's work.

\section{The current situation in the technical infrastructure facilities and applications and its effects on urban life}

Each new settlement brings up a need of different technical infrastructure service based on the needs and qualities of the settlement, for having a healthy and livable urban life environment. Even the roads differ from each other in terms of physical locations, structuring, organization and urban function, according to the service type.

\subsection{Planning stages and infrastructure in Turkey}

\subsubsection{Upper scale plans}

According to the related law, technical infrastructure areas are: the electricity, petrol and natural gas lines of public or private sectors, drinking and using water lines, infrastructure and superstructure refining centers, sewages, waste 
processing plants, power distribution units, all kinds of energy facilities, transportation and telecommunication lines, and parking garages and lots. Making an accurate definition of infrastructure and superstructure conditions always brings terms like happiness, durableness, sustainability, and environmental and urban quality with it. Planning legislation that defines the related processes, the institutional and organizational systems built upon this topic, and the valid operation processes are listed as the following:

\subsubsection{Regional planning}

Regional plans are the strategy, coordination and guidance documents that are created to develop an area; to determine the relation between the national policies, plans and strategies, and local events; to strengthen the collaboration and the coordination of the local institutions; to improve the collaboration between the NGO's and private sector; to accelerate the regional development; to provide sustainability in the region; to ensure productive and efficient usage of the resources; and to create a basis for the regional programs and the projects that aim the efficient usage of the resources.

The law also does not draw any boundaries, nor does it create guidance for infrastructure capacity and facilities in the regional scale, and it leaves gaps for the regional plans.

\subsubsection{Spatial strategy plan}

Spatial plans must be made in compliance with the planning stages. They are also supposed to guide the lower plan, according to the staging hierarchy. Spatial strategy plans, environment plans and zooning plans are the plans that guide the area usage and construction. Spatial strategy plans consider the development focuses, new cities, metropolitan regions or the country. They cover the economic regions, development corridors, supply and production movements and relations, urban and regional network, density of the settlement, transportation relations and physical thresholds.

Spatial strategy plans, as they are defined in the 2009 Declaration of the Urbanization Council, are accepted to be "the plan stages that Ministry of Environment and Urbanization prepares by improving the physical planning and construction regulations and standards, with the Ministry of Development. These plans are also in accordance with the development policies, and they indicate national and regional spatial development strategies." Following this definition, according to the 10 Development Plan (2013) principles; "The decisions about detailed area usage, property regulation and application are made in low scale plans. The upper scale plans that lead them are made more strategic. In these plans, the aim, the quality, the extent of the plans and the determination level in area usage are clarified." Spatial strategy plans are the plans that

- Relate the country's development policies with the regional development strategies spatially;

- Evaluate the economic and social potential, aim and strategy with the transportation relations and physical relations; 
- Determine spatial strategies about gaining underground and aboveground resources, protecting and improving the natural, historical and cultural values, and guiding the urban, social and technical infrastructure with the transportation system of the settlement;

- Exist in $1 / 250.000,1 / 500.000$ or upper scale with a graphical and schematic language;

- Can be made in the entire country and wherever it is considered necessary;

- Include sectorial and thematic plates and reports."

\subsubsection{Environmental master plan}

Environmental master plans are made in a basin or a region that has uniform pattern in terms of geography, society, economics, administration, space and function, or at least in one city. An environmental master plan is defined as: "a type of plan that determines the type of the settlement, and usage of the area like industry, agriculture, tourism, transportation, construction, in accordance with the country and region plan decisions." According to the related law, it is defined as: "the plan that is in compliance with the aims of the spatial strategy plan if there is any, and the strategy decisions. These plans show basic geographic data such as forests, lakes, agricultural areas; and they determine the general usage decisions about urban and rural settlement, development areas, industry, agriculture, tourism, transportation, and energy sectors. They also create a protection-usage balance between the sectors and the settlement; and they are displayed on the maps with $1 / 50.000$ or $1 / 100.000$ scale. They can be prepared on the basis of region, basin or city. The regulation states that it is necessary to gather data about the infrastructure systems from the related institutions, to analyze, to study and to research these data in the process of making environmental plans. This planning stage displays the plans in all kinds of scales, programs, strategies, regional-scaled public projects and investment decisions about the planning area, lakes, dams, streams, flow areas, underground and aboveground water resources and similar hydraulic, hydrogeological areas, environmental issues and the affected areas.

\subsubsection{Zooning plans}

Zooning plans, prepared by local governments, create a basis for the applications of the plans, including the form, shape and the social profile that the city will get in the future. In the zooning plans, if the residential usage is located in mixedusage areas, it is necessary to specify the rate of residential usage, and to include social and technical infrastructure that are required for the residential usage. In the zooning plans, in which the residential usage is not specified, it is assumed that the residential usage is $30 \%$ at most (m. 21/10). It is accepted that the social and technical infrastructure areas that do not create environmental pollution will be planned in the areas that are either the property of the institutions responsible of managing the services, or that are under the possession of these institutions and organizations. In the process of making preparation for the planning studies, in terms of the necessary technical basis and analytic studies, infrastructure plays an important role. Infrastructures are considered as the reinforcement areas in the 
preparation process of the maps, the process of locating an existing state, and the preparation of area usage. In this process, the data and information, the documents, the previous plan decisions, the investment decisions and projects, and all the other related data gathered from different public institutions and organizations, carry a great importance.

According to the legislation, the required institutions have to give opinions for the dam and watering projects about reclamation precautions; for the lakes and the flow areas; for the data about maximum water surface quota; for the highways, automobile routes and expropriation profiles and their borders, the crossroad studies; for the railway routes, station lots, and expropriation borders; for the airport lots, expropriation borders, flight cones and enclosure lines-plans; for the high-tension lines, post places, expropriation borders and the necessary protection precautions; the petrol and natural gas piping lines, routes and expropriation borders.

According to the regulation, it is required to create threshold analysis in the preparation of zoning plans. The main topics of this study are topography, geology, geotechnical data, hydrology, land structure, forests, drinking water basins and all of the other natural structural data and qualities, protection areas, protection zones, sensitive areas, shore data, water surfaces, disaster state, and social and technical infrastructure. These will be evaluated altogether.

\subsubsection{Master development plans}

The related regulation defines the master development plans as: "the plans that construct a basis for the general usage forms of the area, and they indicate the population density of the regions in future, primary region types, development route and size of various urban and rural settlement areas and their principles, the technical, urban, social infrastructure areas, and transportation systems. These plans are created in accordance with the general principles, aim and decisions of the environmental plan if there is any." They are prepared in a scale of $1 / 5.000$ with the cadastral status if there is any, in any scale between $1 / 5.000$ to $1 / 25.000$ in metropolitan municipalities, on approved maps, with the plan notes and detail report."

Master development plans show the staging of housing, trading, industry regions, green areas, recreation areas, non-residential areas, and transportation lines. The design of these plans is supposed to shorten the travel distance in the transportation system. Open lots like parks, playpens, and squares are designed as centers of a neighborhood or a district. Open and green areas are planned with the other social and technical infrastructure areas as a whole, with easy access to the centers. In the preparation of master development plans, data about the general topics are gathered from the related institutions and organizations in the frames of planning area, and these data are researched, studied, and analyzed.

Another detail about the technical infrastructure is that according to Law 2560, Directorate of ISKI has to give an opinion about the compliance of the plan with the infrastructure facilities in the preliminary study. Although the decisions about the application are not made in the master development plans, the steps for making the application plans can be determined if necessary. 


\subsubsection{Application plans}

The related regulation defines the application plan as: "the plan that indicates the city blocks, usages, structure order, building height, lot coverage, floor area ratio or equals, structure approach distance, frontage line, parceling line, stage line, city block separation line, vehicle, pedestrian and bicycle roads, transportation relations, parks, squares, urban, social and technical infrastructure areas, parcel sizes, parcel fronts and depths, rear front line, road elevation and number of floors under this elevation, number of independent segments and likewise decisions about construction and application, application steps as the basis of the application programs, and other information in details. These plans consider the conditions of the region and the general features of the planning areas, usage purpose of the structure and its needs, accessibility, sustainability and its effects on the environment, and they are prepared in accordance with the principles and the basis of master development plans, in a scale of 1/1.000 with the cadastral status, on approved maps with the plan notes and the detailed report." Spatial usage decisions and principles of the regulation are defined in 5/1-k: "Spatial usage is the general name given to usages like electricity, petrol and natural gas transmission lines that the public or private sector makes, petrol and natural gas transmission lines, drinking and usage water, underground and aboveground refining, sewage, waste processing facilities, power distribution center, all kinds of facilities that are made for providing services like energy, transportation, telecommunication, and parking garages and parking lots." The application plans also include details about the relations between the infrastructure facilities and application. Some of the important issues about technical infrastructure in the clauses of application in Spatial Plan Making Regulation (m. 24) can be listed as the following:

- Application plans can be made in single or multiple steps considering the balance of the social and technical infrastructure area;

- Location and size of the social and technical infrastructure areas that are indicated in the master development plans can be changed in the application plans by considering the opinions of the related institutions and organizations, with the conditions of staying in the service area, not damaging the general operation, entireness, and the main decisions of the master development plan, and the condition of not getting below the total standards;

- In the application plans, the functions that augment the number of social and technical infrastructure areas such as playpen, green area, parking garage, road size parking lot, rest areas, family health centers, prayer room, police station, mukhtar's office, energy distribution center can be separated, and imposing these functions will not be considered as a contradiction to the master development plans;

- Application plans must improve the social and technical infrastructure services. A change that lowers the standards of technical and social infrastructure cannot be made, and these standards are foreseen in the application plan in force; 
- Except for the foreseen way in the application plan, removal or size reduction of the social and technical infrastructure areas, and the social and cultural facility areas that belong to the community can only be made by sparing a new area that is equal to the service area that. In sparing the equal area, the surface area and location features are protected. In changing the locations of these areas, it is required for them to stay in the same region or application stage according to the service area in the plan. The planners must consider the pedestrian access distance, and the new area must be available for making the facility;

- In the application plan changes that augment the density or affect the urban transportation system, a report and an analysis is prepared about the evaluation of urban technical infrastructure influence. By this way, the influences on the urban technical infrastructure are determined, and the necessary precautions are taken.

\subsubsection{Urban design projects}

Urban design projects are defined in the related Regulation as: "the projects that include mass and structuring order or outdoor regulations based on the designing purpose, by considering the natural, historical, cultural, social and economic qualities, and the area structure. These projects construct vehicle transportation, parking garage and service relations, and pedestrian cycle relations, and they show details about structure, street, texture, open and green area relations and urban decoration. They also elaborate infrastructure factors with an integrated approach in an inter-disciplinary way, and express the symbol, meaning and identity qualities. They include the principles and tools of design, in a proper scale." As a result, planning is the main determinant for creating, constructing infrastructure systems for development, renovating, and strengthening the "smart cities", which are irreplaceable for a sustainable growth.

\section{Conclusions}

The chaotic structure of the planning stages and the organs in charge create a danger zone for infrastructure as well. Especially, the absence of an integrated capacity definition in upper scale plans for infrastructure is one of the most bothering factors in this issue. However, having an urban capacity definition made by an urban system, and determining infrastructure need based on this, would be realistic. In this context, the main guides of the infrastructure system are the upper scale acceptance, tendency, risk and potentials like the growth policies, energy policies, natural resource usage and policies, geographic, topographic and natural values, thresholds, settlement size, population density, user densities like day and night user distribution, summer and winter population distribution, working areas like industry, trading, central working areas, official organizations, economic structure, social profile, user/consumer pattern and behaviors. Under the light of these basic data, the urban infrastructure systems would function and be interpreted in a systematic, supplementary and continuous relation with the engineering basic fields, without a doubt. One of the main 
problems about planning is the amount of legal regulations, and the amount of authorized organs. Apparently, the legal plan making authority that many ministry and organization have complicates the practice. Plus, the authorization problem divided in different institutions weakens the connection between the upper scale plans.

One of the main troubles about urbanization and settlement in Turkey is the absence of an active spatial planning system. The upper scale plans, the city plans and the application cannot get integrated. The primary issue is providing the social and technical infrastructure needs in order to ensure safe, healthy and livable settlements. At this point, the settlement staging is the determinant of the infrastructure distribution, and the administration of urban and infrastructure systems to utilize the infrastructure facilities.

With the function changes that occur with the segmental plan changes, the change decisions in the density, and the construction values that get to the building block scale raise another risk. This risk is the necessity of application and project decisions, plans, and infrastructure calculations that must carry an integrated approach with the decisions of these changes. However, one of the most important problems in application is the absence of any change in infrastructure calculation, acceptance, project designing principles against the changing plan decisions, density and population values. This problem leads infrastructure to become unfavorable for the population capacity. Eventually, infrastructure becomes insufficient, and it creates an obstacle in creating livable, healthy and sustainable cities.

\section{References}

[1] Şahin, S.Z., Kent Planlama Süreci İle Kentsel Altyapı İlişkilerinin Değerlendirilmesi: Ankara Örneği www.imo.org.tr

[2] T.C. Çevre ve Şehircilik Bakanlığ1 2015 Altyapı Tesislerine Ait Usul ve Esasların Belirlenmesine İlişkin 1. Ara Rapor.

[3] T.C. Bayındırlık İskan Bakanlığı 2009, Kentleşme şurası Komisyon Raporları. 